\title{
A new understanding of the relationship between sugars, dental caries and fluoride use: implications for limits on sugars consumption
}

\author{
Aubrey Sheiham ${ }^{1, *}$ and W Philip T James ${ }^{2}$ \\ ${ }^{1}$ Department of Epidemiology \& Public Health, University College London, 1-19 Torrington Place, London WC1E \\ 6BT, UK: ${ }^{2}$ London School of Hygiene and Tropical Medicine, London, UK, and World Obesity, London, UK
}

Submitted 1 October 2013: Final revision received 7 April 2014: Accepted 2 May 2014: First published online 3 June 2014

\begin{abstract}
Objective: To examine the quantitative relationship between sugar intake and the progressive development of dental caries.

Design: A critical in-depth review of international studies was conducted. Methods included reassessing relevant studies from the most recent systematic review on the relationship between levels of sugars and dental caries. Reanalysis of dose-response relationships between dietary sugars and caries incidence in teeth with different levels of caries susceptibility in children was done using data from Japanese studies conducted by Takeuchi and co-workers.

Setting: Global, with emphasis on marked differences in both national sugar intake and fluoride use and preferably where one factor such as sugar intake changed progressively without changes in other factors over a decade or more.

Subjects: Children aged 6 years or more and adults.

Results: Caries occurred in both resistant and susceptible teeth of children when sugar intakes were only 2-3\% of energy intake, provided that the teeth had been exposed to sugars for $>3$ years. Despite increased enamel resistance after tooth eruption, there was a progressive linear increase in caries throughout life, explaining the higher rates of caries in adults than in children. Fluoride affects progression of caries development but there still is a pandemic prevalence of caries in populations worldwide.

Conclusions: Previous analyses based on children have misled public health analyses on sugars. The recommendation that sugar intakes should be $\leq 10 \%$ of energy intake is no longer acceptable. The much greater adult burden of dental caries highlights the need for very low sugar intakes throughout life, e.g. 2-3\% of energy intake, whether or not fluoride intake is optimum.
\end{abstract}

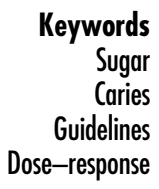

Sugars are undoubtedly the most important dietary factor in the development of dental caries ${ }^{(1-8)}$ and dental caries is the most common chronic disease in the world ${ }^{(9)}$. Treating caries is responsible for $6-10 \%$ of total health costs, even though there has been a decline in dental caries levels in many countries ${ }^{(10,11)}$. A significant relationship between sugars and caries persists despite the regular wide-scale use of fluoride toothpaste and fluoridated water ${ }^{(4,5)}$.

Recommendations by national governments and the WHO on a safe level of sugar intake suggest that intakes should be less than $10 \%$ of energy intake (\%E) based on the shape of the dose-response relationship between national sugar intakes and incidence of dental caries within one year post eruption in the permanent incisor teeth of 12 -year-old children ${ }^{(1)}$. That approach, first developed by Sheiham ${ }^{(6,7,12)}$, was in keeping with
Newbrun's proposition from animal studies of a sigmoidshaped curvilinear relationship between level of dietary sugars and caries incidence ${ }^{(13)}$. That dose-response relationship became the accepted basis for establishing a limit on ideal sugar intakes and for monitoring dental caries in 12-year-old children as the basis for assessing acceptable levels of sugar consumption ${ }^{(14)}$. The worldwide prevalence of dental caries is still unacceptably high in adolescents and adults despite the decrease in severity in 12-year-olds ${ }^{(11)}$. Therefore, the objectives of the present paper were to examine: (i) the quantitative relationship between sugar intakes and the progressive development of dental caries; (ii) the validity of using a sigmoid-shaped curvilinear relationship between the level of dietary sugars and caries incidence in children; and (iii) whether the current dental approach mainly using topical fluoride or 
water fluoridation markedly reduces caries levels in adults. In the current paper, sugar intakes in different studies were considered as free sugars, added sugars, sucrose, non-milk extrinsic sugars or total sugars.

\section{Methods}

A critical in-depth review of previous international studies was conducted. The studies included had both sugar intakes monitored with detailed examination of the caries prevalence of individual teeth by trained professionals, taking account of the national state of fluoridation of water and the use of fluoridated toothpastes. Methods included reviewing relevant studies included in the most recent systematic review and meta-analysis conducted by Moynihan and Kelly $^{(4)}$ on the relationship between levels of sugars and dental caries. A reanalysis of the dose-response between dietary sugars and caries incidence in teeth with different levels of susceptibility to dental caries in children was carried out using data from the classic Japanese studies conducted by Takeuchi and co-workers. Takeuchi analysed caries rates in each tooth type and by post-eruptive tooth age in large representative cohorts of Japanese children from before, during and after World War II ${ }^{(15-20)}$. Each tooth was monitored annually in children of known ages during the period when sugar intakes dropped dramatically in World War II to a low of $0.2 \mathrm{~kg} /$ capita per year, i.e. $\approx 0.1 \% \mathrm{E}$, in 1946. These data are unique in relating the speed and differential tooth sensitivity to dental caries with different prevailing sugar intakes.

Analyses were undertaken of two lower-income countries, Tanzania and China, with sugar intakes below $15 \%$ E. Data were also analysed from an Iraqi study where sugar intakes changed markedly over several years due to UN sanctions $^{(21)}$.

The diagnosis of caries was based on overt dental cavitation, despite the process of caries development having a long pre-cavitation phase ${ }^{(22,23)}$. Nevertheless, for a conservative analysis, the review was confined to the quantification of cavitated caries incidence and accumulated rates.

\section{Results}

A scrutiny of a previous systematic review ${ }^{(4)}$ and an update on developments in 2012 and 2013, together with an analysis of FAO food balance sheets ${ }^{(24)}$, revealed that sugar intakes in most countries are now well in excess of $10 \% \mathrm{E}$, so either historical data or unusual settings were required to assess the full range of sugar intakes and their impact on caries development.

\section{Reanalysis of Takeuchi studies}

Takeuchi ${ }^{(15-20)}$ and co-workers noted marked differences in tooth susceptibility to caries: incisor teeth had about twice the resistance to caries compared with molar teeth.
There was a log-linear relationship to sugar intakes and caries across the spectrum of exposures to sugars (Fig. 1). When the choice of teeth was standardised, the time since the teeth had erupted was also important (Fig. 2). The incidence of caries continued at very low sugar intakes even in teeth that had been erupted for 12 years, i.e. when children were entering adulthood. The cumulative effect of these processes was then evident in both susceptible (molar teeth, see Fig. 3(b)) and the most resistant incisor teeth (Fig. 3(a)) by the time 8 years had elapsed after tooth eruption, e.g. with children aged between 14 and 16 years on the maximum sugar intake of $30 \mathrm{~kg} /$ year $(16.4 \% \mathrm{E})$. Then $70 \%$ of this group had dental caries. Even on $10 \% \mathrm{E}$, equivalent to about $18.25 \mathrm{~kg} / \mathrm{capita}$ per year, a third of these children had dental caries in their most resistant teeth, the incisors. The studies were conducted before, during and after World War II when per capita average sugar levels decreased from $15 \mathrm{~kg} /$ year $(\approx 8.2 \% \mathrm{E})$ to $0.2 \mathrm{~kg}(\approx 0.1 \% \mathrm{E})$ and then increased to levels above $25 \mathrm{~kg} /$ year $(\approx 13.7 \% \mathrm{E})^{(15)}$.

\section{Studies in populations with low sucrose intakes}

Numerous studies from decades ago showed that in countries where sugar consumption was very low, dental caries was almost non-existent ${ }^{(25-27)}$. Sheiham reported that $98 \%$ of Nigerians of all ages had no experience of caries in $1964^{(25)}$. In 1938 sugar consumption of inhabitants of the Island of Tristan da Cunha was $1.8 \mathrm{~g} /$ capita per $\mathrm{d}(0.4 \% \mathrm{E})$ and in 1937 the proportion of 13-19-year-olds with caries was $2 \%$. Sugar intakes increased to $150 \mathrm{~g} / \mathrm{d}(30 \% \mathrm{E})$ by 1966 and the prevalence of caries increased to $17.5 \%$. In $40-49$-year-olds the increase was from $11 \%$ to $32 \%{ }^{(26,27)}$.

New analyses from low-income countries like Tanzania and China, with sugar intakes of $9.08 \mathrm{~kg} /$ capita per year $(5 \% \mathrm{E})$ and $6.9 \mathrm{~kg} /$ capita per year $(3.8 \% \mathrm{E})$, respectively, showed caries levels eight to nine times higher in adults than in children. The number of decayed, missing and filled teeth (DMFT) was 0.30 in Tanzanian and 0.53 in Chinese 12 -year-olds compared with 2.9 and 4.5 , respectively, in 35-44-year-olds.

\section{Effects of wartime sugar rationing and sanctions}

Meta-analyses confirm the statistical relationship between the average sugar intakes and the prevalence of caries $^{(4,28,29)}$, reinforcing the ecological studies with in effect national interventions induced by wartime sugar rationing and sanctions on sugar imports. Iraq $^{(21)}$ showed the marked responsiveness of caries to prevailing sugar intakes: levels of dental caries in Iraqi children halved after UN sanctions that reduced sugars from $50 \mathrm{~kg} /$ capita per year $(27.4 \% \mathrm{E})$ before sanctions to $12 \mathrm{~kg} /$ capita per year $(6 \cdot 6 \% \mathrm{E})$ five years later (Table 1$)^{(21)}$. Similar but less detailed observations come from World War II studies in Norway and Britain ${ }^{(30-32)}$. Norwegian children aged 6-12 years consuming about $28.5 \mathrm{~g}$ sugar/d (5.7\%E) had lower caries levels than pre-war levels, but the prevalence was still high ${ }^{(30)}$. In Britain, wartime sugar consumption 


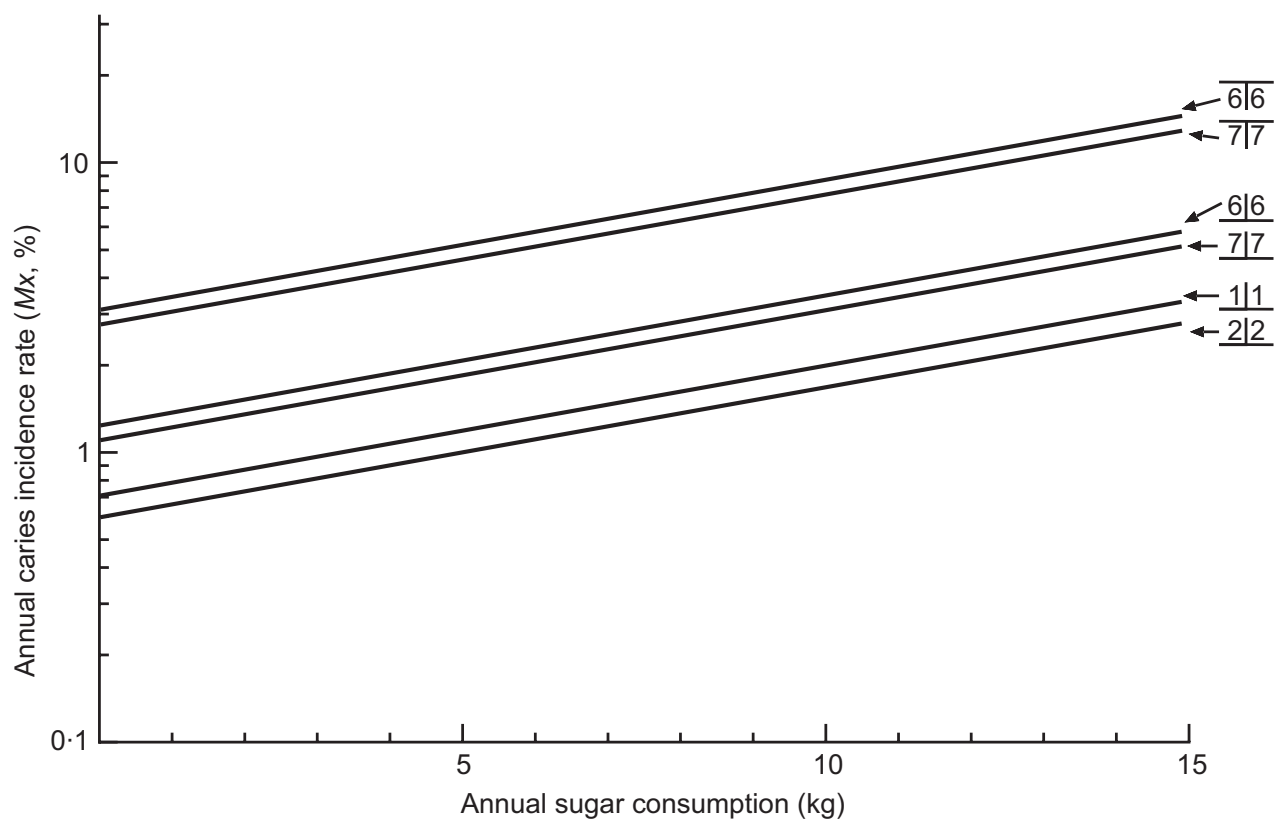

Fig. 1 Regression lines of the correlation between annual sugars consumption and annual caries incidence rates by type of teeth $^{(12)}$. The average caries rates on a log-linear scale are shown for the two first molars (tooth number 6 ) with the bar at the top representing the molars in the upper jaw and the bar at the bottom representing those in the lower jaw; the average caries rates for tooth number 7 relate to the second upper and second lower molars. Tooth 1 is the central lower and tooth 2 the lateral lower incisors. Note the incisors are more resistant than the molars, which show the same incidence of cavitation at about half the sugar intake needed for the incisors. Sugar intakes of $5 \mathrm{~kg} /$ capita per year are equivalent to about $2.7 \% \mathrm{E}$ and $15 \mathrm{~kg} / \mathrm{capita}$ per year to $8.2 \% \mathrm{E}$, where $\% \mathrm{E}$ is percentage of energy intake. (Adapted from Sheiham ${ }^{(12)}$ )

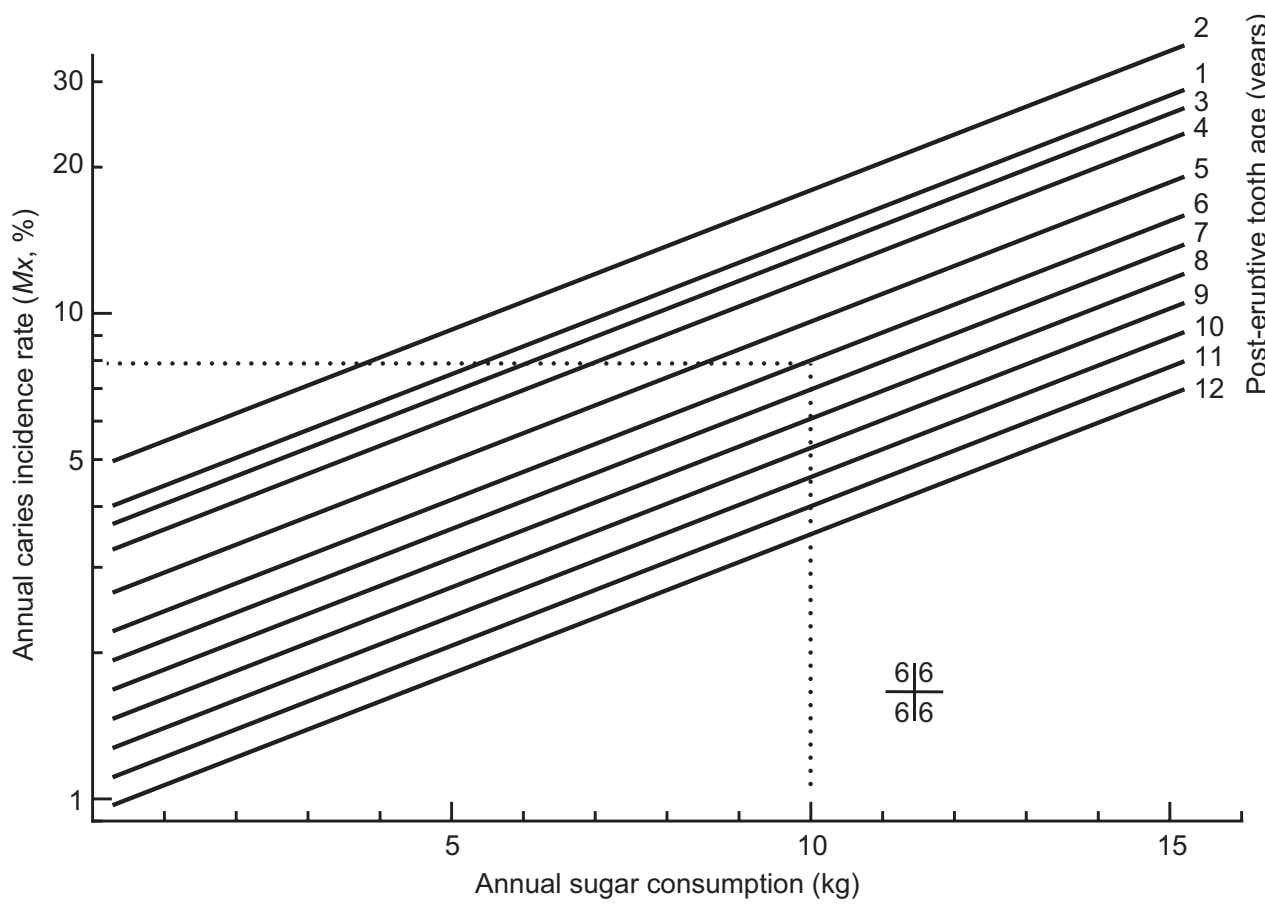

Fig. 2 The incidence rates $(M x)$ for different post-eruptive years, from 1 to 12 years, and annual sugar consumption for the upper and lower first molars (tooth number 6), showing the slowly increasing resistance of teeth to sugar-induced caries after their eruption but with a log-linear effect still evident in older teeth that have been exposed for $10-12$ years ${ }^{(15)}$. Mx, the annual caries incidence rate $=$ number of teeth newly attacked by caries during $x$ years of post-eruptive age/number of sound teeth at $x$ years of posteruptive age. (Adapted from Takeuchi ${ }^{(15)}$ ) 

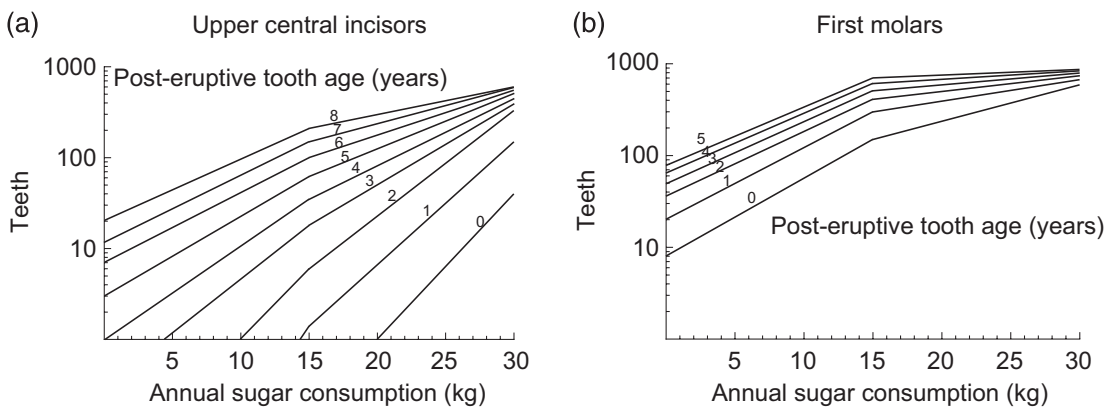

Fig. 3 Cumulative numbers of upper central teeth (a) and first molar teeth (b) affected by caries per 1000 teeth plotted on a log scale, by post-eruptive tooth age and annual sugars consumption ${ }^{(16)}$. In 1971 , when these data were published, the average national sugar intake in Japan from FAO food balance sheets was about $11.7 \% \mathrm{E}(\approx 21.4 \mathrm{~kg} / \mathrm{year})$, where \%E is percentage of energy intake. (Adapted from Takeuchi et al. ${ }^{(16)}$ )

Table 1 Levels of dental caries in Iraqi children before and after the UN sanctions (UNS) that reduced sugars from $50 \mathrm{~kg} / \mathrm{capita}$ per year $(27.4 \% \mathrm{E})$ before UNS, to $12 \mathrm{~kg} /$ capita per year $(6.6 \% \mathrm{E})$ five years later ${ }^{(21)}$

\begin{tabular}{lcc}
\hline Age & dmft/DMFT before UNS & dmft/DMFT after UNS \\
\hline $6-7$ years* & & \\
Urban & 6.5 & 3.3 \\
Rural & 1.9 & 0.7 \\
11-12 years & & \\
Urban & 5.4 & 2.5 \\
Rural & 1.3 & 0.5
\end{tabular}

$\% \mathrm{E}$, percentage of energy intake; dmft/DMFT, decayed, missing and filled teeth.

${ }^{*}$ Dental caries data for 6-7-year-olds include caries in the primary dentition (dmft), whereas data for older age group are for the permanent dentition (DMFT).

fell to $30 \mathrm{~kg} /$ capita per year $(\approx 16.4 \% \mathrm{E})$ and led to a $43 \%$ decrease in caries in 12 -year-olds but $74 \%$ still had four or more decayed teeth. However, $51 \%$ of Jersey children aged 3-7 years eating about $160 \mathrm{~g}$ sucrose/week (or $\approx 4.6 \% \mathrm{E}$ ) until 1944 were caries free compared with $11 \%$ of children evacuated from Jersey to England ${ }^{(32)}$. Using data from eighteen countries in 1959 on the relationship of sucrose consumption and average number of DMFT of 10-12-year-old children, Buttner ${ }^{(33)}$ revealed a high positive correlation: $r=0 \cdot 95$.

\section{Dental caries in adults}

Dental caries is commonly considered a disease of children. However, as will be shown here, it is apparent that more caries occurs in adults than in children. This indicates that a sugars-induced dental disease progresses despite the recent decline in dental caries in children ${ }^{(34)}$. Figures 1 and 2 apply to Japanese children over half a century ago where the water supply was not fluoridated and when fluoride toothpastes were unavailable. New analyses from Japan ${ }^{(35)}$, but taking surveys of all age groups spanning the last half a century reveal that the rate of accumulation of caries continues in adulthood with a maximum accumulation evident in the fourth decade of life (Fig. 4). So the burden of caries is far greater in adults than in the 12-years-olds usually monitored in epidemiological studies. The progressive secular increase in dental caries in the 30-80-year-olds is consistent with the slowly increasing sugars content of the Japanese diet. In the young, however, there has been a declining incidence since about 1980 when sugar consumption levels decreased and fluoride toothpastes in Japan became increasingly available $^{(35)}$ (Fig. 4).

Given the interactions between sugar-induced caries and the preventive role of careful repeated dental checks with plaque removal and improved dental hygiene and the use of toothbrushing, cohort analyses in affluent societies were sought. Figure 5 shows recent data from a longitudinal study in Dunedin, New Zealand where preventive dental work and specific advice on daily toothbrushing with fluoride toothpaste continued for 27 years in 955 children from 5 to 32 years of age ${ }^{(36)}$. There is no suggestion of any diminution in the linear rate of caries development on sugar intakes varying from about $15.3 \% \mathrm{E}$ in 1973 to $17.5 \% \mathrm{E}$ in 2000 . Thus despite the extensive repeated dental care and use of fluoride toothpaste, caries persisted and progressively increased with age in the majority of subjects.

Even when high percentages of the water supplies have been fluoridated as in Australia ${ }^{(37)}$ and Ireland ${ }^{(38)}$, there was an increase in DMFT with age and most of the disease was in adults, not children. In Australia, mean numbers of DMFT and decayed and filled tooth surfaces increased tenfold from the youngest to the oldest age groups. Adults with $>75 \%$ of lifetime exposure to fluoridation relative to $<25 \%$ of lifetime exposure had $11 \%$ and $10 \%$ fewer DMFT and reductions of $30 \%$ and $21 \%$ in decayed and filled tooth surfaces in the pre-1960 and 1960-1990 cohorts, respectively $^{(37)}$. In Ireland with fluoridated water supplying drinking water to $73 \%$ of the population for over 50 years, the number of DMFT in 12-year-olds was 1.30 and in 35-44-year-olds was 15.0. Their 2000-2002 National Dental Survey showed that the numbers of DMFT of persons in non-fluoridated and fluoridated areas were $5.2 v .4 .6$ in 16-24-year-olds, 16.0 v. 13.3 in 35-44-yearolds and $26.7 v$. 25.9 for $\geq 65$-year-olds, respectively ${ }^{(38)}$. 


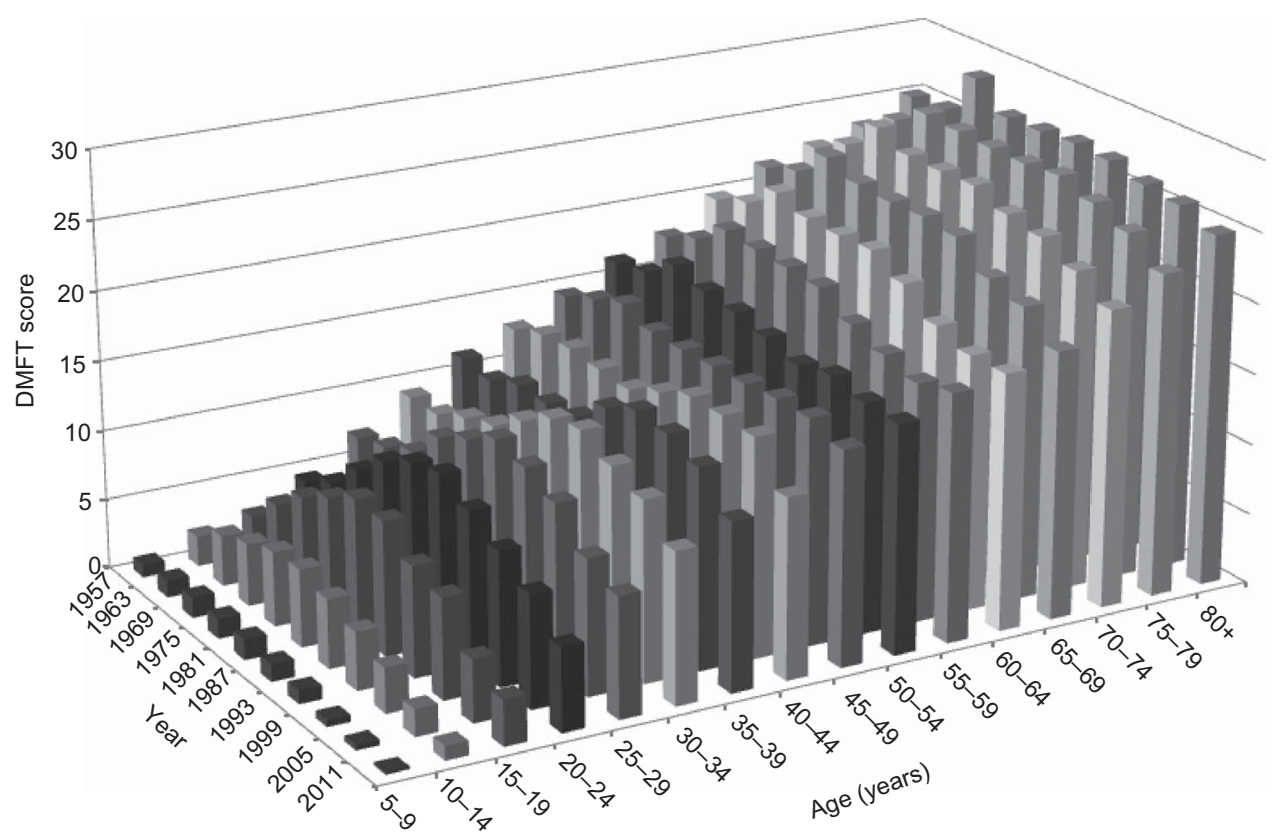

Fig. 4 Mean numbers of decayed, missing and filled teeth (DMFT) in Japan from nine national dental surveys conducted at 6-year intervals from 1957 to 2005 and presented sequentially for each age group from 1957 to 2005, showing the increase in DMFT with age and that most of the increase in DMFT occurred in adults ${ }^{(35)}$. FAO food balance sheet data suggest sugar intakes of $7 \% \mathrm{E}$ in 1961 increasing to $11.2 \% \mathrm{E}$ in 1985 and with intakes of $9.6 \% \mathrm{E}$ in 2005 , where \%E is percentage of energy intake. (Adapted from Kawashita et al. ${ }^{(35)}$ )

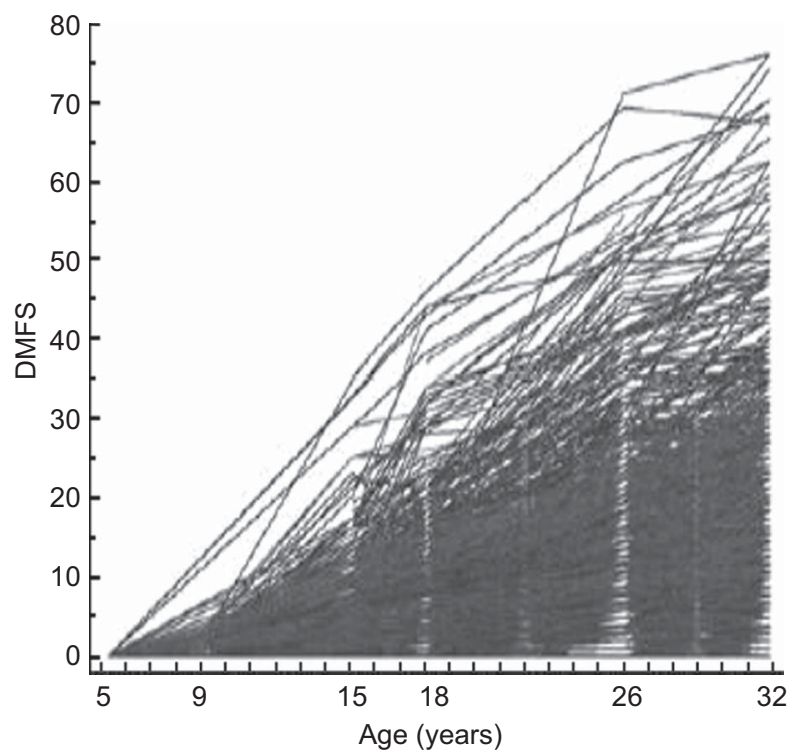

Fig. 5 Trend lines showing increasing levels of caries of individuals when aged 5 years and followed through into adulthood until they are 32 years of age. Each line depicts the caries level of an individual, where DMFS is decayed, missing and filled surfaces ${ }^{(36)}$. (Published with permission)

\section{Discussion}

The most remarkable data on the relationship between dietary sugars and caries in man come from the meticulous sequential studies in Japan ${ }^{(15-20)}$ where it became clear that the dose-response relationship is log-linear or arithmetically curvilinear even though the diagnostic level of caries used was cavitation; a late stage of caries ${ }^{(39)}$. There is no evident threshold for sugars below which there are no adverse effects. So in children there is a log-linear relationship in increased rates of caries even for sugar intakes between $2 \mathrm{~kg} /$ year $(\approx 1.0 \% \mathrm{E})$ and $5-7.5 \mathrm{~kg} /$ year $(\approx 2.7 \%-4.1 \% \mathrm{E})$ in teeth erupted for 7-8 years. However, Fig. 5 emphasises that whatever the prevailing level of relatively high sugar intake, the actual annual accumulation of caries progresses linearly throughout life.

The unique feature of the detailed repetitive Japanese data proved important in showing differential susceptibility to caries by tooth type and post-eruptive tooth age. Lower first molars are the most susceptible and incisors the least ${ }^{(40,41)}$ and the regression lines between incidence of caries and annual sugar consumption differed for each kind of tooth ${ }^{(18)}$. At each level of sugar consumption incidence of caries was higher in lower than upper molars; upper incisors were the least susceptible (Fig. 1). Okuya ${ }^{(19)}$ showed that when annual per capita sugar consumption decreased from $15 \mathrm{~kg}(\approx 8.2 \% \mathrm{E})$ to $10 \mathrm{~kg}(\approx 5.5 \% \mathrm{E})$, caries in second molars decreased but did not become zero. The correlation between sugars and caries was +0.7 and was log-linear, not sigmoid as previously suggested. The lowest caries prevalence (25\%) in 6-11-year-olds occurred between 1949 and 1951 when sugar levels were $<15 \mathrm{~kg} /$ year $(<8.2 \% \mathrm{E})^{(17)}$. These prevalences were similar to those in various European countries with wartime sugar rationing ${ }^{(42)}$.

The fact that the relationship to dental caries holds for increases and decreases in sugars consumption in any 
given community limits the possibility of confounders affecting the relationship and shows that there is no 'safe' level of sugars for caries, contrary to what Sreebny ${ }^{(14)}$ suggested. Even the most resistant upper central incisors had caries at sugar intakes $<5 \mathrm{~kg} /$ year $(\approx 2.7 \% \mathrm{E})$ after they had been erupted for four or more years. For the susceptible molar teeth, a sugar intake of $15 \mathrm{~kg} /$ year $(\approx 8 \cdot 2 \% \mathrm{E})$ seems almost maximal in its caries impact with only 3-5 years' exposure in Japanese children without much, if any, fluoride ${ }^{(18)}$. Indeed, 8 years post eruption molar teeth show a doubling in caries rates between sugar intakes of about zero and $5 \mathrm{~kg} /$ year $(\approx 2.7 \% \mathrm{E})$. This curvilinear dose-response relationship is supported by a later study in Japanese 12-year-olds by Miyazaki and Morimoto $^{(43)}$, who showed a positive log-linear correlation of 0.91 and caries increasing as sugar consumption rose to a peak at $29 \mathrm{~kg} /$ year $(\approx 15.9 \% \mathrm{E})$ in 1973 .

Early data from the WHO dental database clearly showed that even at low sugar availability levels in the 1970 s, in countries with sugar consumption of $<50 \mathrm{~g} / \mathrm{d}$ $(<10 \% \mathrm{E})$ such as Bangladesh, Ethiopia, Nigeria and in Togo, where sugar intakes were $<20 \mathrm{~g}$ sugar/capita per d $(<4 \% \mathrm{E})$, the number of DMFT in 12-year-old children was still 1.5 or above. These rates were higher than in some industrialised countries.

There are numerous later studies showing a strong relationship between sugars consumption and caries rates in children $^{(14,44-47)}$. Extrapolating from such studies suggested that for each increase of $25 \mathrm{~g} / \mathrm{d}(5 \% \mathrm{E})$ in sugars, one tooth per child would become $\mathrm{DMF}^{(39)}$ in the short term. Similarly, Szpunar et $a l .{ }^{(45)}$ found that each additional $5 \mathrm{~g} / \mathrm{d}(1 \% \mathrm{E})$ predicted a $1 \%$ increase in caries in their short-term (3-year) longitudinal study in a fluoride-rich, low-caries environment of 11-15-year-old US children.

The WHO originally accepted Sreebny's 1982 proposition $^{(14)}$ that $50 \mathrm{~g} / \mathrm{d}(10 \% \mathrm{E})$ intake was acceptable when the number of DMFT was below 3 in 12-year-old children. With the then high level of dental caries in children in affluent societies in the 1970 s, WHO considered that a goal of DMFT of 3 for dental health in 12-year-olds ${ }^{(48)}$ was appropriate. Thus the concept of $50 \mathrm{~g} / \mathrm{d}$ as a safe sugars level seems to have been the basis for several countries to agree a daily sugars load of $50 \mathrm{~g}$ as the acceptable limit. So the proposition arose that $10 \%$ of daily energy from sugars was acceptable to both governments and $\mathrm{WHO}^{(1)}$. This meant that there was then little concern for the fact that numerous publications from low- and high-income countries such as the UK showed a significant linear dose-response relationship between caries in children and sucrose availability and that caries was highly prevalent in countries with sugar levels below $10 \% \mathrm{E}$. Unfortunately, the acceptability of $50 \mathrm{~g} / \mathrm{d}(10 \% \mathrm{E})$ sucrose limit was reinforced by the very selective choice of finding an increased cavitation rate in less susceptible teeth that had only been erupted for one year in 6-12-year-olds when sugar intakes were nearly $10 \% \mathrm{E}^{(12)}$.

\section{The progressive nature of caries. Why the majority of caries occurs in adults, not in children}

A major shortcoming of most research on the relationship between sugars and caries is that the relationship in adults has been largely ignored, with all the conclusions being based on children's studies. That is equivalent to drawing conclusions on the relationship between consumption of fats and non-communicable diseases by looking only at children. Caries rates have declined in children with hardly any change in the total amount of sugars available in the diet, so some dental authorities have concluded erroneously that sugars are not a major determinant of caries provided fluoride toothpaste is used diligently. However, the majority of caries occurs in adults, not in children, because the disease is cumulative and rates of caries in individuals track from early childhood to adolescence and then into adulthood ${ }^{(49)}$. In China as well as in Japan the cumulative effect of caries is evident, with the number of DMFT being 0.53 in 12-year-olds in 2005 compared with 4.0 in 35-44-year-olds and 14.6 in 65-74-year-olds ${ }^{(50)}$ at a time when the availability of sugar corresponds to about $3.3 \%$ E. Indeed, universally, the majority of caries occurs in adults, not in children ${ }^{(35,50-53)}$. In a new study of twenty-six countries, very much higher caries levels were observed in adults than in children in all the countries studied. There was a fivefold increase in number of DMFT in 35-44-year-olds compared with 12-year-olds, with greater proportions of adults than children affected in all those countries ${ }^{(53)}$. When annualised, the combined coronal and root surface caries increments experience of older people was between $0 \cdot 8$ and 1.2 new surfaces affected per year when sugar intakes were in the range of $14-18 \% \mathrm{E}$, and exceeded increments reported for adolescents $^{(54)}$. So the major burden of dental diseases and costs associated with caries as well as periodontal disease occurs in adults.

One reason why most caries occurs in adults is that fluoride, the main reason for the recent decline in caries in children, does not stop the progress of the caries process on some susceptible tooth sites ${ }^{(55)}$. The role of fluoride in caries prevention is ascribed to its ability to induce fluoroapatite formation from solutions of calcium and phosphate. It enhances remineralisation as $\mathrm{pH}$ is lowered by sugars and inhibits demineralisation of the tooth enamel, as fluoroapatite is less soluble than hydroxyapatite. Small amounts of fluoride in solution around the tooth inhibit demineralisation more effectively than incorporated fluoride and have a much greater caries-protective potential than a large proportion of fluoroapatite in enamel mineral. Fluoride also interferes with acid production from

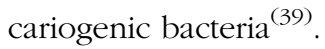

\section{The costs of dental caries}

Dental diseases are the most common of all chronic diseases in both industrial societies and lower-income countries $^{(9)}$. Their impact on individuals and society 
includes pain, discomfort, social and functional limitation and handicap, and effects on the quality of life ${ }^{(56)}$. So the financial impact is relatively high. The treatment of dental diseases costs $5-10 \%$ of total health expenditure in industrialised countries, with WHO estimating oral diseases as the fourth most expensive diseases to treat in most industrialised countries ${ }^{(9-11)}$.

Current analysis indicates that the treatment of caries in low-income countries by traditional restorative dentistry for the permanent dentition would cost between $£ 1024$ (\$US 1618) and £2224 (\$US 3513) per 1000 children of mixed ages from 6 to 18 years. The cumulative cost of treating caries in children exceeds the financial resources available for the whole health care of children in the majority of poor nations, even before the greater costs of caries affecting adults are considered ${ }^{(57)}$.

\section{Indirect costs and impaired quality of life from dental caries}

The costs increase if we take into account the resulting loss of productivity from the 164 million hours of work lost each year in the USA due to dental diseases and dental visits $^{(58)}$. In summarising the costs Casamassimo et al. ${ }^{(59)}$ noted that in the Philippines toothache is the most common reason for absence from school, which is likely to have a substantial impact on the child's learning and therefore on his/her future earnings. In Thailand, 1900 hours of school were lost per 1000 children in 2008 because of dental problems and treatment ${ }^{(60)}$. In Sri Lanka, $53 \%$ of 6-year-olds and in South Africa, $88 \%$ reported having experienced oral pain in their lifetime ${ }^{(61,62)}$.

\section{Impacts on children's growth}

A most important impact that caries and its consequences have on children is that the disease process affects their growth and weight gain ${ }^{(63)}$. Children aged 3 years old with caries weighed about $1 \mathrm{~kg}$ less than control children ${ }^{(64)}$ because toothache and infection alter eating and sleeping habits, dietary intake and metabolic processes. Disturbed sleep also affects the stress-related glucosteroid production. In addition, there is fall in blood Hb levels stemming from the infection-induced depression of erythrocyte production. Two controlled clinical trials have shown that young children with many untreated caries lesions are more likely to be underweight. Extraction of the severely affected teeth led to increases in weight gain. In addition, the children's quality of life was improved after extraction of carious teeth: they slept and ate better ${ }^{(65,66)}$.

\section{Globalisation and demographic changes}

During the past decade, repeated scientific reports signal an alarming increase in the global prevalence of dental caries in children's and adults' primary and permanent teeth, as well as coronal and root surfaces ${ }^{(67)}$. This coincides with the increasing penetration of lower-income markets by transnational companies and the marketing of soft drinks, confectionery and sugar-containing foods to previously unexposed lower-income countries. The severity of caries has become so serious in developing countries that a new dental index of caries, the PUFA index, has been developed: $\mathrm{P}=$ Pulp involvement, $\mathrm{U}=$ Ulceration of mucosa from caries, $\mathrm{F}=$ Fistula from abscess due to caries, $\mathrm{A}=$ Abscess due to caries ${ }^{(68)}$.

It is also important to recognise that the demography of lower-income countries is changing rapidly as fertility rates decline and life expectancy increases. Our previous focus on children's dental health, while proper, now needs to be reframed in a public health context where, given the huge pressures on health-care budgets and the burgeoning populations of older adults in Africa, the Middle East, Asia and Latin America, there needs to be a new emphasis on the role of sugar intakes in inducing major suffering, demands for health care and societal costs. Clearly what is needed is a radical approach to limiting sugar intakes as well as ensuring that fluoride use in water and/or toothpastes is still promoted. Fluoridation, however, cannot be considered a substitute for major efforts to reduce population sugar intakes.

\section{Acknowledgements}

Acknowledgements: The authors are grateful for the help of Dr Shinsho Fumiaki in providing them with a translation of the relevant papers from Japan that allowed them to undertake these new analyses. Financial support: This research received no specific grant from any funding agency in the public, commercial or not-for-profit sectors. Conflicts of interest: None. Authorship: The idea for the paper was conceived by W.P.T.J. A.S. provided the scientific material and content for the paper and obtained permission for reproducing the graphs. Both authors drafted the paper. Ethics of human subject participation: Ethical approval was not required.

\section{References}

1. World Health Organization (2003) Diet, Nutrition and the Prevention of Chronic Diseases. Joint WHO/FAO Consultation. WHO Technical Report Series no. 916. Geneva: WHO.

2. Moynihan P (2005) The interrelationship between diet and oral health. Proc Nutr Soc 64, 571-580.

3. Moynihan P \& Petersen PE (2004) Diet, nutrition and the prevention of dental diseases. Public Health Nutr 7, 201-226.

4. Moynihan P \& Kelly S (2014) Effect on caries of restricting sugars intake: systematic review to update WHO guidelines. J Dent Res 93, 8-18.

5. Marthaler TM (1990) Changes in the prevalence of dental caries: how much can be attributed to changes in diet? Caries Res 24, Suppl. 1, 3-15.

6. Sheiham A (1983) Sugars and dental decay. Lancet i, 282-284.

7. Sheiham A (2001) Dietary effects on dental diseases. Public Health Nutr 4, 569-591. 
8. Zero DT (2004) Sugars - the arch criminal? Caries Res 38, 277-285.

9. Petersen PE, Bourgeois D, Ogawa H et al. (2005) The global burden of oral diseases and risks to oral health. Bull World Health Organ 83, 661-669.

10. Beaglehole R, Benzian H, Crail J et al. (2009) The Oral Health Atlas: Mapping a Neglected Global Health Issue. Brighton: Myriad Editions.

11. Patel R (2012) The State of Oral Health in Europe. http://www.oralhealthplatform.eu/sites/default/files/field/ document/A5-Summary-BOHEP_State\%20of\%20Oral\%20 Health_Executive\%20Summary_A5_FINAL.pdf (accessed September 2013).

12. Sheiham A (1991) Why free sugars consumption should be below $15 \mathrm{~kg}$ per person per year in industrialised countries: the dental evidence. Br Dent J 171, 63-65.

13. Newbrun E (1982) Sucrose in the dynamics of the carious process. Int Dent J 32, 13-23.

14. Sreebny LM (1982) Sugar availability, sugar consumption and dental caries. Community Dent Oral Epidemiol 10, 1-7.

15. Takeuchi M (1961) Epidemiological study on dental caries in Japanese children, before, during and after World War II. Int Dental J 11, 443-457.

16. Takeuchi M, Shimizu T, Takehisa K et al. (1971) Sealing of the pit and fissure with resin adhesive: IV. Results of fiveyear field work and a method of evaluation of field work for caries prevention. Bull Tokyo Dent Coll 12, 295-316.

17. Takeuchi M, Pu M-Y, Shimizu T et al. (1980) Dental caries in the central mountain district in Taiwan, The Republic of China. Report 1: Results of survey in 1971 and 1972. J Dent Health 29, 44-53.

18. Takahashi K (1959) Statistical study on caries incidence in the first molar in relation with amount of sugar consumption. Jpn J Oral Hyg 9, 136-150.

19. Okuya Y (1960) The epidemiological study of the relation between caries incidence and sugar consumption on the second molar. Shikwa Gububo 60, 1120-1134.

20. Koike H (1962) Studies on caries incidence in the first molar in relation to amount of sugar consumption on primary school children in Kyoto city. Bull Tokyo Dent Coll 3, 44-56.

21. Jamel H, Plasschaert A \& Sheiham A (2004) Dental caries experience and availability of sugars in Iraqi children before and after the United Nations sanctions. Int Dent J 54, 21-25.

22. Mejàre I, Kallestal C, Stenlund $\mathrm{H}$ et al. (1998) Caries development from 11 to 22 years of age: a prospective radiographic study. Caries Res 32, 10-16.

23. Mejàre $\mathrm{H}$, Stenlund $\mathrm{C} \&$ Zelezny-Holmlund C (2004) Caries incidence and lesion progression from adolescence to young adulthood: a prospective 15-year cohort study in Sweden. Caries Res 38, 130-141.

24. Food and Agriculture Organization of the United Nations (2013) FAO food balance tables. http://faostat.fao.org/site/ 368/default.aspx\#ancor (accessed August 2013).

25. Sheiham A (1967) The prevalence of dental caries in Nigerian populations. Br Dent J 123, 144-148.

26. Holloway PJ (1963) Dental disease in Tristan da Cunha. Br Dent J 115, 19-25.

27. Fisher FJ (1968) A field survey of dental caries, periodontal disease and enamel defects in Tristan da Cunha. Br Dent $J$ 125, 447-453.

28. Downer MC (1999) Caries experience and sucrose availability: an analysis of the relationship in the United Kingdom over fifty years. Community Dent Health 16, 18-21.

29. Masood M, Masood Y \& Newton T (2012) Impact of national income and inequality on sugar and caries relationship. Caries Res 46, 581-588.

30. Toverud G (1957) The influence of war and post-war conditions on the teeth of Norwegian schoolchildren. Millbank Mem Fund Q 35, 127-196, 373-459.
31. Schulerud A (1950) Dental Caries and Nutrition During Wartime in Norway. Oslo: Fabritius and Sonners trykkeri.

32. Knowles EM (1946) The effects of enemy occupation on the dental condition of children in the Channel Islands. Monthly Min Health 1946, August, 162-167.

33. Buttner W (1971) Zuckeraufnahme und karies. In Grundfragen der Ernäbrungswissenschaft, pp. 175-191 [HD Cremer, editor]. Freiburg im Breisgau: Rombach. Cited by Marthaler TM (1979) In Health and Sugar Substitutes. Proceedings of ERGOB Conference on Sugar Substitutes, p. 27 [B Guggenheim, editor]. Basel: Karger.

34. Petersson GH \& Bratthall D (1996) The caries decline: a review of reviews. Eur J Oral Sci 104, 436-443.

35. Kawashita Y, Kitamura M \& Saito T (2012) Monitoring time-related trends in dental caries in permanent teeth in Japanese national surveys. Int Dent J 62, 100-105.

36. Broadbent JM, Thomson WM \& Poulton R (2006) Progression of dental caries and tooth loss between the third and fourth decades of life: a birth cohort study. Caries Res 40, 459-465.

37. Slade GD, Sanders AE, Do L et al. (2013) Effects of fluoridated drinking water on dental caries in Australian adults. J Dent Res 92, 376-382.

38. Whelton H, Crowley E, O'Mullane D et al. (2007) Oral Health of Irish Adults 2000-2002 - Final Report - April. Dublin: Department of Health and Children.

39. Fejerskov O (2004) Changing paradigms in concepts on dental caries: consequences for oral health care. Caries Res 38, 182-191.

40. Batchelor P \& Sheiham A (2004) Grouping of tooth surfaces by susceptibility to caries: a study in 5-16 year-old children. BMC Oral Health 4, 2.

41. Korhonen M, Käkilehto T \& Larmas M (2003) Tooth-bytooth survival analysis of the first caries attack in different age cohorts and health centers in Finland. Acta Odontol Scand 61, 1-5.

42. Sognnaes RF (1948) Analysis of wartime reduction of dental caries in European children. Am J Dis Child 75, 792-821.

43. Miyazaki H \& Morimoto M (1996) Changes in caries prevalence in Japan. Eur J Oral Sci 104, 452-458.

44. Silverstein SJ, Knapp JF, Kircos L et al. (1983) Dental caries prevalence in children with a diet free of refined sugar. Am J Public Health 73, 1196-1199.

45. Szpunar SM, Eklund SA \& Burt BA (1995) Sugar consumption and caries risk in schoolchildren with low caries experience. Community Dent Oral Epidemiol 23, 142-146.

46. Rodrigues CS \& Sheiham A (2000) The relationships between dietary guidelines, sugar intake and caries in primary teeth in low income Brazilian 3 year olds: a longitudinal study. Int J Paediatr Dent 10, 47-55.

47. Routtinen S, Karjalainen S, Pienihakkinen K et al. (2004) Sucrose intake since infancy and dental health in 10-yearold children. Caries Res 38, 142-148.

48. Anon. (1982) Global goals for oral health by the year 2000. Fédération Dentaire Internationale. Int Dent J 32, 74-77.

49. Sheiham A \& Sabbah W (2010) Using universal patterns of caries for planning and evaluating dental care. Caries Res 44, 141-150.

50. Xiaoqiu Qi (2008) Report of Third National Survey of Oral Health Status in China. Beijing: People's Medical Publishing House (in Chinese).

51. Hugoson A, Koch G, Helkimo AN et al. (2008) Caries prevalence and distribution in individuals aged 3-20 years in Jönköping, Sweden, over a 30-year period (1973-2003). Int J Paediatr Dent 18, 18-26.

52. Hugoson A \& Koch G (2008) Thirty year trends in the prevalence and distribution of dental caries in Swedish adults (1973-2003). Swed Dent J 32, 57-68.

53. Bernabé E \& Sheiham A (2014) Extent of differences in dental caries in permanent teeth between childhood and adulthood in 26 countries. Int Dent J (In the Press). 
54. Thomson WM (2004) Dental caries experience in older people over time: what can the large cohort studies tell us? Br Dent J 196, 89-92.

55. Groeneveld A (1985) Longitudinal study of prevalence of enamel lesions in a fluoridated and non-fluoridated area. Community Dent Oral Epidemiol 13, 159-163.

56. Slade GD (1997) Measuring Oral Health and Quality of Life. Chapel Hill, NC: University of North Carolina.

57. Yee R \& Sheiham A (2002) The burden of restorative dental treatment for children in Third World Countries. Int Dent J 52, $7-10$.

58. US Department of Health and Human Services (2000) Oral Health in America: A Report of the Surgeon General. Rockville, MD: US DHHS, National Institute of Dental and Craniofacial Research, NIH.

59. Casamassimo PS, Thikkurissy S, Edelstein BL et al. (2009) Beyond the dmft: the human and economic cost of early childhood caries. J Am Dent Assoc 140, 650-657.

60. Pongpichit B, Sheiham A, Pikhart $\mathrm{H}$ et al. (2008) Time absent from school due to dental conditions and dental care in Thai schoolchildren. J Public Health Dent 68, 76-81.

61. Ratnayake N \& Ekanayake L (2005) Prevalence and impact of oral pain in 8-year-old children in Sri Lanka. Int J Paediatr Dent 15, 105-112.
62. Naidoo S, Chikte UME \& Sheiham A (2001) Prevalence and impact of dental pain in 8-10-year-olds in the Western Cape. S Afr Dent J 56, 521-523.

63. Sheiham A (2006) Dental caries affects body weight, growth and quality of life in pre-school children. Br Dent $J \mathbf{2 0 1}$, 625-626.

64. Acs G, Lodolini G, Kaminski S et al. (1992) Effect of nursing caries on body weight in a pediatric population. Pediatr Dent 14, 302-305.

65. Monse B, Duijster D, Sheiham A et al. (2012) The effects of extraction of pulpally involved primary teeth on weight, height and BMI in underweight Filipino children. BMC Public Health 12, 725.

66. Alkarimi HA, Watt R, Pikhart H et al. (2012) Impact of treating dental caries on schoolchildren's anthropometric, dental, satisfaction and appetite outcomes: a randomized controlled trial. BMC Public Health 12, 706.

67. Bagramian RA, Garcia-Godoy F \& Volpe AR (2009) The global increase in dental caries. A pending public health crisis. Am J Dent 22, 3-8.

68. Monse B, Heinrich-Weltzie R, Benzian H et al. (2010) PUFA - an index of clinical consequences of untreated dental caries. Community Dent Oral Epidemiol 38, $77-82$. 